\title{
Are Audience Response Systems Worth the Cost? Comparing Question-Driven Teaching Strategies for Emergency Medical Technician Education
}

\author{
Lauren M. Maloney \\ Stony Brook University School of Medicine, lauren.maloney@stonybrookmedicine.edu \\ James P. Dilger \\ Stony Brook University School of Medicine, james.dilger@stonybrookmedicine.edu \\ Paul A. Werfel \\ Stony Brook University, paul.werfel@stonybrook.edu \\ Linda M. Cimino \\ Stony Brook University School of Medicine, linda.cimino@stonybrookmedicine.edu
}

Follow this and additional works at: https://nsuworks.nova.edu/ijahsp

Part of the Curriculum and Instruction Commons, Educational Assessment, Evaluation, and Research Commons, Educational Methods Commons, and the Emergency Medicine Commons

\section{Recommended Citation \\ Maloney LM, Dilger JP, Werfel PA, Cimino LM. Are Audience Response Systems Worth the Cost? Comparing Question-Driven Teaching Strategies for Emergency Medical Technician Education. The Internet Journal of Allied Health Sciences and Practice. 2018 Jan 01;16(1), Article 8.}

This Manuscript is brought to you for free and open access by the College of Health Care Sciences at NSUWorks. It has been accepted for inclusion in Internet Journal of Allied Health Sciences and Practice by an authorized editor of NSUWorks. For more information, please contact nsuworks@nova.edu. 


\title{
Are Audience Response Systems Worth the Cost? Comparing Question-Driven Teaching Strategies for Emergency Medical Technician Education
}

\begin{abstract}
Purpose: As Emergency Medical Technician educators develop curricula to meet new national educational standards, effective teaching strategies validated for course content and unique student demographics are warranted. Three methods for answering multiple choice questions presented during lectures were compared: a) Audience Response System (ARS, clickers), b) hand-raising-with-eyes-closed (no-cost option), and c) passive response (no-cost option). The purpose was to determine if using the ARS resulted in improved exam scores. Method: 113 Emergency Medical Technician (EMT) students participated in this cross-over, block randomized, controlled trial, which was incorporated into their Cardiac Emergencies and Pulmonary Emergencies course lectures. Students took pretests, immediate post-tests, and delayed posttests composed of multiple choice questions that targeted either lower or higher order thinking. Results: For both lectures, there were significant improvements on all immediate post-test scores compared to all pretest scores ( $p$ Conclusions: In this cohort, incorporation of no-cost question-driven teaching strategies into lectures was as effective as an ARS at encouraging significant, immediate and sustained improvements in answering multiple choice questions.
\end{abstract}

\section{Author Bio(s)}

Lauren M. Maloney, MD, NRP, FP-C, NCEE, is a Resident Emergency Medicine Physician in the Department of Emergency Medicine at Stony Brook University School of Medicine. Additionally, she has a Bachelor's of Engineering in Biomedical Engineering, and is a board certified flight paramedic, and nationally certified Emergency Medical Services educator.

James P. Dilger, PhD is a professor in the Departments of Anesthesiology and Physiology and Biophysics at Stony Brook University. His laboratory research concerns the effects of anesthetics and other drugs on ion channels in nerve and muscle cells. He has extensive experience with statistical analysis of data.

Paul A. Werfel, MS, NRP a professor of clinical Emergency Medicine, Clinical Assistant Professor of Health Science, and the Director of the EMT and Paramedic Program, at Stony Brook University. Additionally, he is a prolific international speaker and well published author following several decades of work as a paramedic.

Linda M. Cimino, EdD, MSRN, CPNP, ANP, CCRC, CHSE is an associate professor in Stony Brook University's Schools of Medicine, Nursing, Health Technology and Management and Pharmacological Sciences and holds certifications as Nurse Practitioner in Child and Adult Health, and Coordinator of Clinical Trials Research. Expertise includes instructional design planning/assessments/evaluations. 


\title{
IJAHSP \\ The Internet Joưnal of Allied Health Sciences and Practice \\ Dedicated to allied health professional practice and education
}

Vol. 16 No. 1 ISSN 1540-580X

\section{Are Audience Response Systems Worth the Cost? Comparing Question- Driven Teaching Strategies for Emergency Medical Technician Education}

\author{
Lauren M. Maloney, MD, NRP, FP-C, NCEE \\ James $P$. Dilger, $P h D$ \\ Paul A. Werfel, MS, NRP \\ Linda M. Cimino, EdD, MSRN, CPNP, ANP, CCRC, CHSE \\ Stony Brook University \\ United States
}

\begin{abstract}
Purpose: As Emergency Medical Technician educators develop curricula to meet new national educational standards, effective teaching strategies validated for course content and unique student demographics are warranted. Three methods for answering multiple choice questions presented during lectures were compared: a) Audience Response System (ARS, clickers), b) handraising-with-eyes-closed (no-cost option), and c) passive response (no-cost option). The purpose was to determine if using the ARS resulted in improved exam scores. Method: 113 Emergency Medical Technician (EMT) students participated in this crossover, block randomized, controlled trial, which was incorporated into their Cardiac Emergencies and Pulmonary Emergencies course lectures. Students took pretests, immediate post-tests, and delayed post-tests composed of multiple choice questions that targeted either lower or higher order thinking. Results: For both lectures, there were significant improvements on all immediate post-test scores compared to all pretest scores $(p<0.0001)$. Improvements were made on both lower and higher order questions. The response method had no significant effect on test $s c o r e s(p=0.3)$. Conclusions: In this cohort, incorporation of no-cost question-driven teaching strategies into lectures was as effective as an ARS at encouraging significant, immediate and sustained improvements in answering multiple choice questions.
\end{abstract}

\section{INTRODUCTION}

As Emergency Medical Services educators develop curricula to meet new national standards, additional content must be incorporated into already tight course schedules. ${ }^{1,2}$ Emergency Medical Technician (EMT) course content is often delivered through lectures utilizing textbook companion slides. However, educators are being encouraged to incorporate goal-directed active learning and real-time feedback into lesson plans. ${ }^{3} \mathrm{~A}$ common solution is to incorporate Audience Response Systems (ARS) into PowerPoint based lectures ${ }^{4-7}$ These "clickers" wirelessly transmit an individual's answer to multiple-choice questions (MCQs) and provide real-time display of student responses.

Literature initially lauded ARS incorporation into lectures. Immediately assessing the students' understanding of the content allowed educators to tailor the lecture, either by revisiting misunderstood concepts or by omitting content already familiar to students. $5,6,8,9$ Student response rates to questions posed by educators have been correlated with scholastic achievement, therefore, it is unsurprising that a teaching tool which encourages student participation would be beneficial. ${ }^{10}$ Additionally, students may acquire improved and deeper understanding when presented with well-structured questions that target a specific learning objective, expose common misconceptions, or put familiar material into a new context.

According to Bloom's Taxonomy of the Cognitive Domain, there are six major hierarchical categories of cognitive process: knowledge, comprehension, application, analysis, synthesis, and evaluation. ${ }^{2}$ Analysis, synthesis, and evaluation are considered higher order thinking skills indicative of content mastery and may be demonstrated by students as they assess and respond to carefully crafted questions. ${ }^{2,11}$ Such questions are likely to encourage students to reflect upon and reprocess the presented 
material.5,9,12-15 Additionally, asking students to commit to an answer seems to increase their engagement in follow-up discussions. ${ }^{16}$ This student-educator interactivity, combined with immediate individualized feedback to students, further supports effective adult learning. ${ }^{17}$

Many initial studies of ARS directly compared ARS-supplemented lectures to traditional non-interactive lectures. Rubio et al. randomized radiology residents into two groups, one group receiving a traditional non-interactive lecture and the other group receiving a lecture that incorporated multiple-choice questions and ARS use. ${ }^{18}$ There was a statistically significant increase in scores on a post-test given immediately after the lecture and again 3 months later for the group that used the ARS as compared to the scores earned by the group who received the traditional lecture. Additionally, Pradhan et al. divided obstetrics and gynecology residents into two groups, again with one group receiving a traditional lecture and the other receiving a lecture with embedded MCQs that were answered with an ARS. ${ }^{6}$ Residents who participated in the ARS enhanced lecture demonstrated improvements on post-test scores from their pre-test scores that were greater and statistically significant than those score improvements achieved by the traditional lecture group. However, this type of comparison has been cautioned because showing students MCQs during a lecture may alert them to important concepts, thus preparing them for post-lecture evaluations, independent of ARS use. $6,7,13,19,20$ Some studies reviewed did not employ both pre-and post-lecture evaluations, ${ }^{18,21}$ and most did not describe the types of questions presented during the lecture or on evaluations. 5,6,18,21,22 Additionally, the mechanism whereby active learning facilitated by ARS encourages higher order thinking is not clearly understood.9,17,23 Test score improvements seen with an ARS may be due to the overall change from a passive teaching style to one that encourages active participation and draws attention to important concepts via well-structured MCQs. ${ }^{9,17,23}$ As such, non-technological alternative question-driven teaching strategies such as hand or card raising could produce similar results, though the lack of anonymity and inability of educators to note individual responses makes these lower-cost alternatives less appealing. 9,17,22

Although well-controlled studies evaluating ARS-supplemented lectures are beginning to be published, no papers specifically address the prehospital provider population. ${ }^{24-26}$ As the scope of practice of prehospital emergency medicine providers continues to increase in complexity, safe and appropriate patient care logically depends on the education of providers. Many are required to have only a high school diploma prior to enrollment in a training program. Therefore, there is a need for time and cost-effective teaching strategies that have been validated for the specific content and demographics unique to prehospital care providers.

The objective of this study was to use MCQ pretests, immediate post-tests, and delayed post-tests formatted to demonstrate lower and higher order thinking to evaluate different response methods for question-driven teaching strategies. Our primary aim was to evaluate if there was a significant difference in exam scores as a result of each teaching strategy. Secondarily, we wanted to evaluate if there would be a significant difference in higher order question scores and or lower order question scores, depending upon teaching strategy used. These strategies were incorporated into cardiac and pulmonary emergency lectures delivered to EMT students. Response methods included an ARS using a clicker and two no-cost, universally available response options: hand raising with eyes closed (HREC) and only displaying the MCQ (passive MCQ).

\section{METHODS}

This cross-over, block randomized, controlled trial of EMT students was reviewed by the local Institutional Review Board and granted educational exempt status. All students enrolled in three original EMT classes, sponsored by the Stony Brook University School of Heath Technology and Management, were included in this study. Each cohort (X, Y, and Z) was composed of approximately 50 different individuals and had identical course content and evaluation schedules. Before the first lecture, students completed a demographic questionnaire to verify cohorts had enough consistent student traits to allow for appropriate cross-comparison. Additionally, students created their own unique identifiers that allowed questionnaire and test responses to be linked anonymously.

Two lectures, pulmonary emergencies and cardiac emergencies, were chosen for this study as they have comparable depth and breadth of content. Both lectures were 3 hours long and delivered by the same educator to the three cohorts, with other teaching staff randomly sitting in on the classes to ensure consistent teaching style. The same slide set was used each time a lecture (pulmonary or cardiac) was presented. Each lecture emphasized 10 learning objectives with each objective addressed by content slides and an analytical-level MCQ during the lecture.

Before starting the first of the three EMT cohorts, lectures were assigned the teaching strategy to be utilized when a MCQ was presented during the presentation; ARS with clickers and hands-raised-with-eyes-closed (HREC) were alternated in the for the pulmonary and cardiac lectures for two cohorts (cross-over), and the third cohort used passive MCQs for both lectures as a control (Table 1). During ARS lectures, students had to enter an answer with the clicker within 60 seconds. For HREC lectures,

(c) The Internet Journal of Allied Health Sciences and Practice, 2018 
students were asked to close their eyes after 60 seconds and then raise their hands when their answer was read aloud. For the passive MCQs lectures, no solicitation of the correct answer was performed and the correct answer was provided by the instructor after 60 seconds of students viewing the MCQ. For the ARS and HREC lectures, students were verbally told which answer the majority of the class selected. For all three strategies, once the correct MCQ answer was revealed, the educator facilitated a class discussion of the key details in the question and relevant features of the answers.

Table 1: Teaching strategies were assigned to the Pulmonary Emergencies Lecture and Cardiac Emergencies Lecture for each of the three EMT cohorts (X, Y, Z).

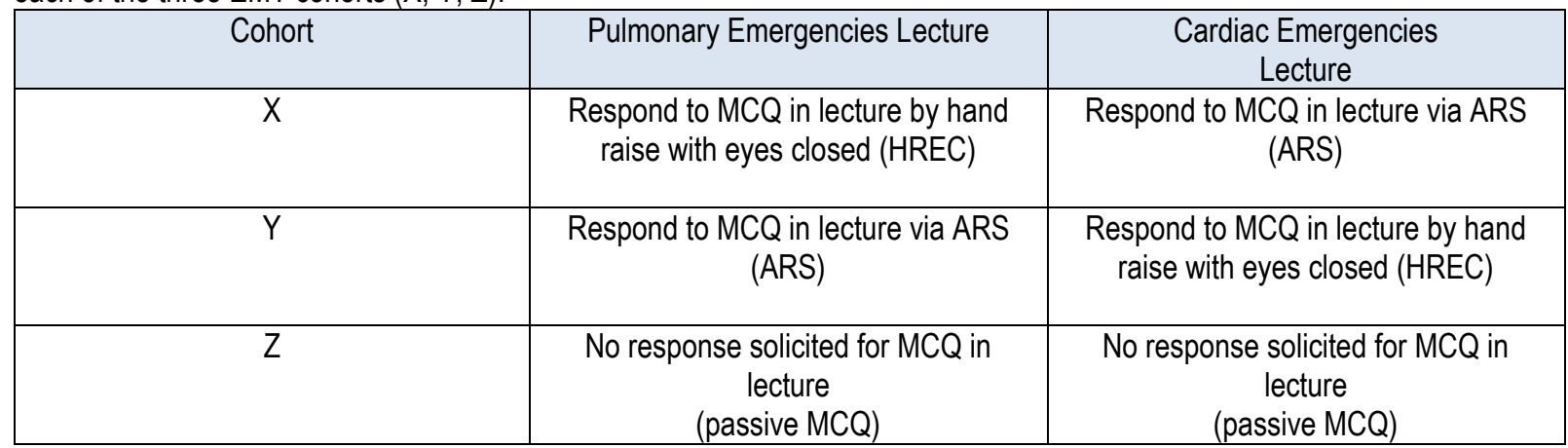

EMT = emergency medical technician; ARS = Audience Response System with clicker; HREC = hand raise with eyes closed; $\mathrm{MCQ}=$ multiple choice question.

In addition to the questions asked during the two lectures, tests specific to each lecture topic were given prior to the start of each lecture (pretest), immediately after each lecture (immediate post-test), and four weeks after each lecture (delayed post-test). Each of the 10 learning objectives highlighted during each of the two lectures were evaluated by two MCQs on their respective tests; one question was designed to assess at Bloom's taxonomy knowledge level and the other designed to assess at the analysis level. Questions were selected from a widely-used test bank. ${ }^{27}$ The same 20 questions in a randomized order were utilized on the pretest, post-test, and delayed post-test. The 20 questions differed from the ones were different from those presented during the lectures and the correct answers on the tests were never revealed. As a result, each student completed six tests (three for each lecture), with a total of 40 unique questions.

A generalized linear regression model for test scores was constructed with the predictors Cohort, Teaching Strategy, and Question Cognitive Level. The model was run using SPSS Statistics Standard GradPack 23 (IBM Corporation, Armonk, NY).

\section{RESULTS}

Data from students who missed any exam were excluded from analysis. Cohorts $X, Y$, and $Z$ had 40,37 , and 36 students, respectively. Variation in student demographics within each cohort was consistent (Table 2) and not statistically significant by chi-squared analysis $(p>0.05)$. 
Table 2. Student Demographic Questionnaire

\begin{tabular}{|c|c|c|c|c|}
\hline & Question & $\begin{array}{c}\text { Cohort X } \\
N=40\end{array}$ & $\begin{array}{c}\text { Cohort } Y \\
N=37\end{array}$ & $\begin{array}{c}\text { Cohort Z } \\
\mathrm{N}=36\end{array}$ \\
\hline \multicolumn{5}{|l|}{ Gender: } \\
\hline & Female & $40 \%$ & $45.9 \%$ & $52.8 \%$ \\
\hline & Male & $60 \%$ & $54.1 \%$ & $47.2 \%$ \\
\hline \multicolumn{5}{|c|}{ Age (years): } \\
\hline & $<22$ & $42.5 \%$ & $46 \%$ & $58.3 \%$ \\
\hline & $22-30$ & $45 \%$ & $40.5 \%$ & $30.6 \%$ \\
\hline & $31-40$ & $7.5 \%$ & $5.4 \%$ & $11.1 \%$ \\
\hline & $41-50$ & $2.5 \%$ & $5.4 \%$ & $0 \%$ \\
\hline & $>50$ & $2.5 \%$ & $2.7 \%$ & $0 \%$ \\
\hline \multicolumn{5}{|c|}{ Highest Education: } \\
\hline & High School & $22.5 \%$ & $16.3 \%$ & $8.3 \%$ \\
\hline & In College & $32.5 \%$ & $37.8 \%$ & $44.4 \%$ \\
\hline & Associates & $7.5 \%$ & $5.4 \%$ & $5.6 \%$ \\
\hline & Bachelors & $35 \%$ & $37.8 \%$ & $38.9 \%$ \\
\hline & Graduate & $2.5 \%$ & $2.7 \%$ & $2.8 \%$ \\
\hline \multicolumn{5}{|c|}{$\begin{array}{l}\text { Time since last formal student } \\
\text { experience: }\end{array}$} \\
\hline & $<1$ year & $77.5 \%$ & $75.7 \%$ & $88.9 \%$ \\
\hline & $1-3$ years & $15 \%$ & $10.8 \%$ & $2.8 \%$ \\
\hline & $>3$ years & $7.5 \%$ & $13.5 \%$ & $8.3 \%$ \\
\hline \multicolumn{5}{|c|}{ Type of study techniques used:* } \\
\hline & Diagrams & 19 & 19 & 18 \\
\hline & Flashcards & 21 & 14 & 7 \\
\hline & Reread & 33 & 30 & 30 \\
\hline & Highlight & 21 & 21 & 23 \\
\hline & Read out loud & 18 & 11 & 11 \\
\hline & Listen to recording & 9 & 5 & 14 \\
\hline & Make models & 3 & 3 & 4 \\
\hline \multicolumn{5}{|c|}{ Self-identified learning style:* } \\
\hline & Visual & 24 & 22 & 23 \\
\hline & Tactile & 21 & 15 & 14 \\
\hline & Auditory & 2 & 7 & 7 \\
\hline
\end{tabular}

${ }^{*}$ Reported as frequency as students could select multiple options

Students were administered MCQ tests before the start of the course, immediately after the course had finished, and 4-weeks after the course had finished. At no time were the answers to these exams presented or discussed.

The generalized linear regression model revealed that Cohort $Y$ scored 3.3 points (out of 100) higher than the other cohorts $(p=0.003)$ and that the immediate and delayed post-test scores for all students improved over their pre-test scores by 18.3 and 20.7 points, respectively $(p<0.0001)$. Overall, students scored 5.8 points higher on the low-order compared to high-order questions $(p<0.0001)$ and 5.8 higher on the pulmonary compared to cardiac questions $(p<0.0001)$. However, the teaching strategy had no significant effect on scores $(p=0.3)$.

Some of these results are illustrated in Figure 1. Figure $1 \mathrm{~A}$ shows that the total score for each cohort increased from pre-test to immediate post-test and that this gain was not diminished from immediate post-test to delayed post-test. Importantly, the increase in pre-test to immediate post-test scores did not depend on the teaching strategy used (Figure 1B). Figures 1C-F 
demonstrate that the increase in scores from pre-test to post-tests was achieved in both the pulmonary and cardiac courses, and for both higher- and lower-order questions.

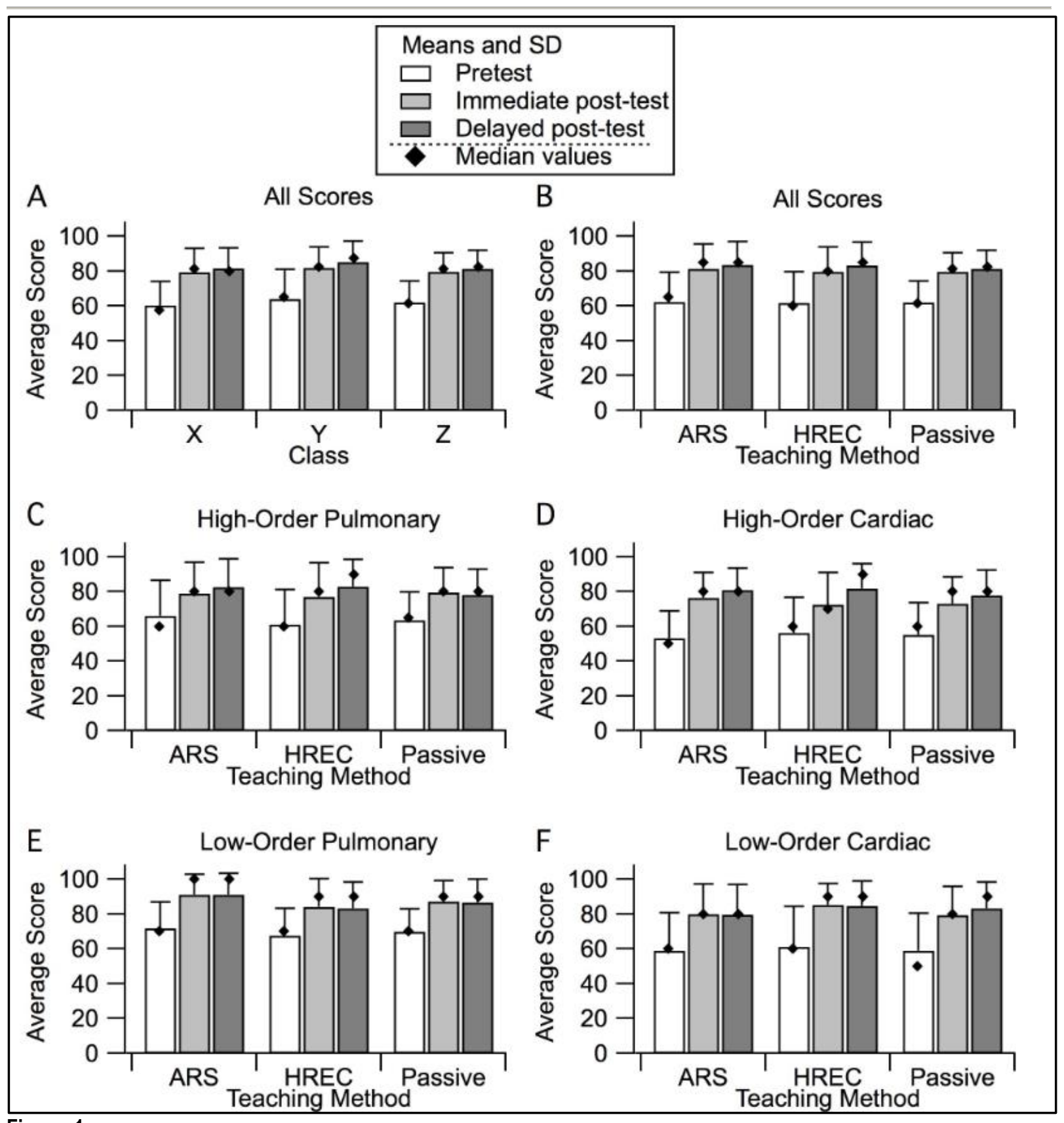

Figure. 1

A. Comparison of the test scores for the three student cohorts; B. Comparison of the test scores for the three teaching methods; C-F. Comparison of the test scores for the three teaching methods separated into high-order and low-order questions from pulmonary emergencies and cardiac emergencies lectures. Means, standard deviations and median values (diamond symbols) are shown; ARS = Audience Response System via clicker; HREC $=$ hand-raise-with-eyes-closed; Passive $=$ questions just displayed to students. 


\section{DISCUSSION}

By using a series of pretests and post-tests composed of MCQs targeting lower and higher order thinking, we aimed to evaluate three different response methods when presenting MCQs to EMT students during pulmonary and cardiac emergency lectures. Our results demonstrate that after presenting students MCQs during the lectures, asking for their input via ARS with clicker, HREC, or not soliciting input at all, in conjunction with instructor-facilitated follow-up discussion, significantly improves immediate post-test scores as compared to pretest scores. These score improvements are demonstrated across both lecture topics, in the higher order and lower order subscores. Most importantly, there were no statistical differences between the teaching tool used and the improvement in scores achieved.

These results are similar to those obtained by others. ${ }^{20,22,23}$ Robson administered pretests and immediate post-tests to dental students presented with MCQs during a lecture. ${ }^{20}$ In that study, one group used an ARS and the other group did not indicate answers. Increases in post-test scores were independent of teaching strategy. ${ }^{20}$ Other studies compared use of an ARS to answer embedded MCQs to simply showing the MCQs to medical or nursing students. ${ }^{23,25}$ Stoddard and Piguette ${ }^{23}$ and Sharma et al.22 found no significant differences between groups on immediate post-lecture exam scores, however, neither administered pretests to assess prior knowledge. Unlike this current study, none of these authors differentiated between higher or lower ordered learning questions. Overall, the current results illustrate the positive effect of teaching strategies that utilize MCQs to highlight important concepts in ways that allow students to reprocess the presented information.

Most MCQs presented during the lectures were designed to stimulate analysis-level cognition that was supplemented with guidance regarding clinical reasoning. These higher order-thinking opportunities may have led to more robust analytical thinking in comparison to knowledge-level cognition demonstrated by the regurgitation of discrete facts. This speaks to the importance of utilizing quality MCQs when facilitating class discussion, as the potential student benefit is only as good as the quality and intent of the question.

Regardless of the response method used, the instructor intentionally facilitated a class discussion of the MCQ after the answer was revealed. For each question, key information in the question stem was identified and each answer choice was discussed in the context of how the incorrect answers could be changed to make them correct and why the correct answer was the best answer given the choices. While some could argue that this "washes out" the impact of the response method, the authors felt that not discussing the questions presented during the class would not be in the best interest of the overall education of the students. Feedback following MCQ presentation potentially allows students to "close the loop" in their understanding of the concept and encourages self-correction of selected responses in future MCQs with which they are presented. ${ }^{28}$ Additionally, feedback after MCQs has been shown to improve student confidence in their knowledge and is felt to be a valuable experience by students. ${ }^{28-30}$ It is difficult to tease out if showing a MCQ to students, or the resulting discussion of the MCQ between students and the educator, were more influential in student learning. We suspect that it was the synergy of the actions that was most influential, regardless of the mechanism by which students disclosed their individual answer.

Student demographics and program location may have influenced the results. Most students in this study are aspiring to advanced healthcare degrees and the educational program is at a large university. The students' learning aptitude may differ from students participating in a community-based EMT program. Additionally, the improvements in test scores may have been due in part to using teaching strategies that target certain learning styles. Most students in this study indicated they were tactile or visual learners.

Although an ARS with clicker provides the most accurate tabulation of student responses, it is an expense that many educational programs may be unable to afford. Our data suggests that universally available, no-cost response methods for question-driven teaching strategies, when coupled with instructor-facilitated follow up discussions, may produce similar educational outcomes and offer an efficient way to encourage deep understanding and retention of course content. Additional research is required to further investigate how well these question-driven teaching strategies globally improve learning outcomes.

(c) The Internet Journal of Allied Health Sciences and Practice, 2018 


\section{REFERENCES:}

1. FEMA. Handbook for EMS Medical Directors. 2012. Available at: https://www.usfa.fema.gov/downloads/pdf/publications/handbook_for_ems_medical_directors.pdf. Accessed on: 13 July 2015.

2. National Highway Traffic Safety Administration. National emergency medical services education standards. Washington DC, USA: US Department of Transportation. 2009. Available at: https://www.ems.gov/pdf/education/EMSEducation-for-the-Future-A-Systems-Approach/National_EMS_Education_Standards.pdf. Accessed on: 2012 December 22.

3. Leinster S. Learning in the clinical environment. Med Teach. 2009;31(2):79-81. 19330666.

4. Allen D, Tanner K. Infusing active learning into the large-enrollment biology class: seven strategies, from the simple to complex. Cell biology education. 2005;4(4):262-268.

5. Kennedy GE, Cutts QI. The association between students' use of an electronic voting system and their learning outcomes. Journal of Computer Assisted Learning. 2005;21(4):260-268.

6. Pradhan A, Sparano D, Ananth CV. The influence of an audience response system on knowledge retention: an application to resident education. Am J Obstet Gynecol. 2005;193(5):1827-1830. 16260243.

7. Homme J, Asay G, Morgenstern B. Utilisation of an audience response system. Medical Educ. 2004;38(5):575. 15107128.

8. Cain J, Robinson E. A primer on audience response systems: current applications and future considerations. Am J Pharm Educ. 2008;72(4):77. 19002277.

9. Caldwell JE. Clickers in the large classroom: current research and best-practice tips. CBE Life Sci Educ. 2007;6(1):920. 17339389

10. Graham CR, Tripp TR, Seawright L, Joeckel G. Empowering or compelling reluctant participators using audience response systems. Active Learning in Higher Education. 2007;8(3):233-258.

11. Thomas E. Thoughtful Planning Fosters Learning Transfer. Adult Learning. 2007;18(3-4):4-8.

12. Kay RH, LeSage A. Examining the benefits and challenges of using audience response systems: $A$ review of the literature. Computers \& Education. 2009;53(3):819-827.

13. Pettit RK, McCoy L, Kinney M, Schwartz FN. Student perceptions of gamified audience response system interactions in large group lectures and via lecture capture technology. BMC Med Educ. 2015;15:92. 25997953.

14. Slain D, Abate M, Hodges B, Stamatakis M, Wolak S. An interactive response system to promote active learning in the doctor of pharmacy curriculum. American Journal of Pharmaceutical Education. 2004;68(5).

15. Dufresne RJ, Gerace WJ, Leonard WJ, Mestre JP, Wenk L. Classtalk: A classroom communication system for active learning. Journal of computing in higher education. 1996;7(2):3-47.

16. Alexander CJ, Crescini WM, Juskewitch JE, Lachman N, Pawlina W. Assessing the integration of audience response system technology in teaching of anatomical sciences. Anat Sci Educ. 2009;2(4):160-166. 19670428.

17. Simpson V, Oliver M. Electronic voting systems for lectures then and now: A comparison of research and practice. Australasian Journal of Educational Technology. 2007;23(2).

18. Rubio El, Bassignani MJ, White MA, Brant WE. Effect of an audience response system on resident learning and retention of lecture material. AJR Am J Roentgenol. 2008 Jun;190(6):W319-22. 18492870.

19. Grzeskowiak LE, Thomas AE, To J, Reeve E, Phillips AJ. Enhancing continuing education activities using audience response systems: a single-blind controlled trial. J Contin Educ Health Prof. 2015;35(1):38-45. 25799971.

20. Robson N, Popat H, Richmond S, Farnell DJ. Effectiveness of an audience response system on orthodontic knowledge retention of undergraduate dental students - a randomised control trial. J Orthod. 2015;42(4):301-14. 26282015.

21. Schackow TE, Chavez M, Loya L, Friedman M. Audience response system: effect on learning in family medicine residents. Fam Med. 2004 Jul-Aug;36(7):496-504. 15243831.

22. Sharma MD, Khachan J, Chan B, O'Byrne J. An investigation of the effectiveness of electronic classroom communication systems in large lecture classes. Australasian Journal of Educational Technology. 2005;21(2).

23. Stoddard HA, Piquette CA. A controlled study of improvements in student exam performance with the use of an audience response system during medical school lectures. Acad Med. 2010;85(10 Suppl):S37-40. 20881700.

24. Atlantis E, Cheema BS. Effect of audience response system technology on learning outcomes in health students and professionals: an updated systematic review. Int J Evid Based Healthc. 2015 Mar;13(1):3-8. 25734861.

25. Vana KD, Silva GE, Muzyka D, Hirani LM. Effectiveness of an audience response system in teaching pharmacology to baccalaureate nursing students. Comput Inform Nursing. 2011 Jun;29(6 Suppl):TC105-13. 21701273.

26. Welch S. Effectiveness of classroom response systems within an active learning environment. J Nurs Educ. 2013 Nov;52(11):653-6. 24127175.

27. Emergency Care and Transportation of the Sick and Injured Instructor's TestBank [computer program]. Jones \&

(c) The Internet Journal of Allied Health Sciences and Practice, 2018 
Bartlett Learning; 2010.

28. Douglas M, Wilson J, Ennis S. Multiple-choice question tests: a convenient, flexible and effective learning tool? A case study. Innovations in Education and Teaching International. 2012;49(2):111-121.

29. Bacon DR. Assessing learning outcomes: A comparison of multiple-choice and short-answer questions in a marketing context. Journal of Marketing Education. 2003;25(1):31-36.

30. Becker WE, Johnston $\mathrm{C}$. The relationship between multiple choice and essay response questions in assessing economics understanding. Economic Record. 1999;75(4):348-357. 